\title{
Assessment in vitro of brushing on dental surface roughness alteration by laser interferometry
}

\author{
Alessandra Miranda de Azevedo(a) \\ Heitor Panzeri(b) \\ Célio Jesus do Prado(c) \\ José Daniel Biasoli De-Mello(d) \\ Carlos José Soares ${ }^{(e)}$ \\ Alfredo Julio Fernandes-Neto ${ }^{(f)}$ \\ (a) DDS, Graduate Student; (b)PhD, Department \\ of Dental Materials and Prosthodontics \\ - School of Dentistry of Ribeirão Preto, \\ University of São Paulo. \\ (c) PhD, Assistant Professor, Department \\ of Removable Prosthodontics; (e) PhD, \\ Department of Restorative Dentistry; ${ }^{(f)} \mathrm{PhD}$, \\ Professor and Chairman, Department of \\ Occlusion, Fixed Prosthodontics, and Dental \\ Materials - School of Dentistry, Federal \\ University of Uberlândia. \\ (d) PhD, School of Mechanical Engineering, \\ Federal University of Uberlândia.
}

\section{Corresponding author:}

Alessandra Miranda de Azevedo

Faculdade de Odontologia de Ribeirão Preto

Universidade de São Paulo (USP)

Departamento de Materiais

Dentários e Prótese

Av. do Café, s/n

Ribeirão Preto - SP - Brazil

CEP: 14040-904

E-mail: aleazevedopa@yahoo.com.br
Abstract: Noncarious cervical lesions (NCCLs) are considered to be of multifactorial origin, normally associated with inadequate brushing. This study assessed the influence in vitro of simulated brushing on NCCL formation. Fifteen human premolars were submitted to brushing in the cementoenamel junction region, using hard-, medium- and soft-bristled brushes associated with a toothpaste of medium abrasiveness under a $200 \mathrm{~g}$ load, at a speed of $356 \mathrm{rpm}$ for 100 minutes. The surface topography of the region was analyzed before and after brushing, by means of a laser interferometer, using "cut-off" values of 0.25 and considering roughness values in $\mu \mathrm{m}$. The initial roughness $(\mu \mathrm{m})$ results for dentin (D / bristle consistency: 1 - soft, 2 - medium and 3 - hard) were as follows: (D1) $1.25 \pm 0.45$; (D2) $1.12 \pm 0.44$; (D3) $1.05 \pm 0.41$. For enamel (E / bristle consistency: 1 - soft, 2 - medium and 3 - hard), the initial results were: (E1) $1.18 \pm 0.35$; (E2) $1.32 \pm 0.25$; (E3) $1.50 \pm 0.38$. After brushing, the following were the values for dentin: (D1) $2.32 \pm 1.99$; (D2) $3.30 \pm 0.96$; (D3) Over 500. For enamel, the values after brushing were: (E1) $1.37 \pm 0.31$; (E2) $2.15 \pm 0.90$; (E3) $1.22 \pm 0.47$. Based on the results of the ANOVA and Tukey statistical analyses $(\alpha=.05)$ it was concluded that soft, medium and hard brushes are not capable of abrading enamel, whereas dentin showed changes in surface roughness by the action of medium- and hard-bristled brushes.

Descriptors: Tooth abrasion; Dentifrices; Toothbrushing. 


\section{Introduction}

Noncarious cervical lesions (NCCLs), generically denominated tooth abrasion, present a variety of forms, and can affect vestibular, lingual and/or proximal surfaces, commonly being of multifactorial origin. ${ }^{1-4}$ Factors as acids, and occlusal and abrasive forces may interact or act separately, thus contributing to the appearance of cervical lesions. ${ }^{3,5-8}$ These lesions may be classified as: erosive, attritive, abfractive and abrasive. ${ }^{9}$ Dental erosion is tooth structure loss by nonbacterial chemical action; $;^{2,5,6,10}$ attrition is wear of one surface against another and abfraction is a wedge-shaped lesion, located at the cementoenamel junction, caused by stress generated by biomechanical force. ${ }^{1,7,11}$

Clinically, the term abrasion refers to pathological wear by objects repeatedly in contact with the teeth. ${ }^{2}$ Brushing with dentifrice is an example of a triple-body abrasion process, in which disaggregated particles slide between the tooth and brush bristles, the size of the abrasive particles and pressure being important factors in the speed at which the surface undergoes abrasion. ${ }^{12}$ However, definition of this process as an isolated etiologic factor for cervical lesions is still controversial. There are studies in which toothbrushing without dentifrice is apparently incapable of abrading enamel and dentin, ${ }^{7,9,13-17}$ as the toothpaste abrasiveness may be caused by a combination of its erosive effect and the mechanical effect of the toothbrush bristles, ${ }^{18}$ while other studies showed that toothbrushing without dentifrice may induce abrasion. ${ }^{19,20}$ Frequency and toothbrushing technique are also factors related to tooth abrasion. ${ }^{21}$

In view of this context, an hypothesis is set forth that brushing and the type of toothbrush result in topographic alteration of human enamel and dentin, characterizing this process as an etiologic factor of noncarious cervical lesions. In order to confirm this hypothesis, this study assessed the topography, in vitro, of human enamel and dentin before and after brushing with soft-, medium- and hard-bristled brushes associated with dentifrice.

\section{Material and Methods Tooth obtainment}

To conduct this study, 15 healthy human pre- molars were selected because they presented high incidence of abrasive lesions, ${ }^{3,22}$ but did not present any type of lesion on the vestibular enamel and root dentin faces, and had been indicated for extraction due to periodontal problems or orthodontic purposes. Teeth that presented any damage resulting from forceps during extraction were excluded. ${ }^{20}$ This study was approved by the Research Ethics Committee, Federal University of Uberlandia (Protocol No. 224/04).

\section{Sample obtainment}

The selected teeth were embedded in polystyrene resin (Aerojet, São Paulo, SP, Brazil), in the proportion of $12 \%$ monomer to $2 \%$ catalyzer. The teeth were placed horizontally with the vestibular face penetrating approximately $1 \mathrm{~mm}$ into a utility wax slide, and afterwards, enveloped by a rectangular $25 \times 10 \times 10 \mathrm{~cm}$ aluminum matrix. Polystyrene resin was poured in till it was full, and when the resin was completely polymerized, the set was detached from the wax and the matrix, removed, with the result that the tooth, except for the vestibular face, was embedded in resin. The samples received a finishing procedure to remove excess resin and to clean them of wax. The samples were identified and stored in distilled water at a temperature of $37^{\circ} \mathrm{C}$ in an oven and then randomly divided into three groups: 1 use of soft-bristled brushes; 2 - use of medium-bristled brushes, and 3 - use of hard-bristled brushes. To define the type of substrate, D was designated to identify Dentin and E, to identify enamel.

\section{Initial surface topography determination}

Initially, the samples were metal-coated (Emitech K550, Emitech Technologies Ltd., Kent, England), by deposit of a thin layer of gold, equivalent to $10^{-6} \mathrm{~mm}$, in order to increase surface reflectivity. Next, the samples were examined by laser interferometry (Microfocus Expert IV, UBM Corporation, Sunnyvale, CA, USA), and measurements were taken by optic reading of pre-determined $4.0 \mathrm{~mm}^{2}$ areas in enamel and $3.0 \mathrm{~mm}^{2}$ areas in dentin. Readings were taken in the central area of the two substrates, $0.5 \mathrm{~mm}$ from the cementoenamel junction. The gross data obtained were 
analyzed by specific software (Mountains Map ${ }^{\circledR}$ 3, Besançon, France), enabling this surface to be characterized with regard to shape and undulation and to calculate surface roughness parameters, using "cut-off" values of $0.25 .^{23}$ The roughness parameter assessed for numerical characterization of the surface was as follows: $S q$, standard deviation of the distribution of surface peak and valley heights, ${ }^{24,25}$ associated with assessment of the functional parameters: $S s k$, symmetry coefficient, the parameter used to measure the symmetry of a profile in relation to the mean plane, and $S k$, flattening coefficient, which describes the form of topography height distribution. The values found for each parameter were statistically analyzed, the parameter $S q$ being submitted to the parametric ANOVA and Tukey tests $(\alpha=.05)$ and $S k$ and $S s k$ expressed in frequency.

\section{Simulated brushing}

After determining initial topography, the samples were washed under running water to remove the gold layer. Next, they were placed inside an ultrasonic vibration device (Thornton, Vinhedo, SP, Brazil) containing distilled water and stayed there for 10 minutes. Then they were washed with soap and water, alcohol and distilled water and then fixed horizontally in the receptacles by means of modeling compound. To perform the abrasion tests, a brushing machine was used comprised of six stainless steel compartments to put the samples in. The test specimen is placed on the internal base of the receptacle, fixed to a metal plate by means of modeling compound (DFL, Rio de Janeiro, RJ, Brazil). The appliance has a support to which the toothbrush is fixed, aligned parallel to the plate, regulated by screws positioned on the sides and top. The machine was set to run a horizontal course of $3.8 \mathrm{~cm}$, applying a $200 \mathrm{~g}$ load at a speed of $356 \mathrm{rpm}$ for 100 minutes, corresponding to 2 years of normal standard tooth brushing. Similar toothbrushs (Tek, Johnson \& Johnson, São José dos Campos, SP, Brazil), with small, oval-headed and round-tipped synthetic bristles of soft, medium and hard consistency were fixed to the supports and adjusted so that a largest number of bristles would come into contact with the sample. Fifteen milliliters of a suspension prepared with $70 \mathrm{ml}$ of distilled water and $70 \mathrm{~g}$ of dentifrice of medium abrasiveness (Contente, Uberlândia, MG, Brazil) were poured into each tray containing the sample, in order to perform brushing for 100 minutes.

\section{Final surface topography determination}

When the brushing ended, the samples were washed under running water and then submitted to ultrasonic vibration (Thornton, Vinhedo, SP, Brazil) for 10 minutes to remove the abrasive particles. The samples were metal-coated again and the surface topography parameters were obtained again, in accordance with the same measuring methodology used initially.

\section{Results}

Mean and standard deviation values of the parameter $S q$ for the human enamel and dentin are presented in Table 1 . The data were submitted to the analysis of normality and homogeneity and were shown to present normal and homogenous distribution for the parameter $S q$. Therefore, statistical analysis was carried out by means of a two-way ANOVA. Post hoc comparisons among

Table 1 - Mean and standard deviation values of the parameter Sq and statistical categories - Tukey Test $(P<0.05)$.

\begin{tabular}{|c|c|c|c|c|c|c|}
\hline \multirow{3}{*}{ Brush type } & \multicolumn{6}{|c|}{ Values in $\mu \mathrm{m}$} \\
\hline & \multicolumn{3}{|c|}{ Dentin } & \multicolumn{3}{|c|}{ Enamel } \\
\hline & Before Brushing & After Brushing & $\Delta \mathrm{V}$ & Before Brushing & After Brushing & $\Delta \mathrm{V}$ \\
\hline Soft & $1.25 \pm 0.45^{a}$ & $2.32 \pm 1.99^{\circ}$ & +1.07 (85\%) & $1.18 \pm 0.35^{a}$ & $1.37 \pm 0.31^{\circ}$ & $+0.19(16 \%)$ \\
\hline Medium & $1.12 \pm 0.44^{\circ}$ & $3.30 \pm 0.96^{b}$ & $+2.18(195 \%)$ & $1.32 \pm 0.25^{\circ}$ & $2.15 \pm 0.90^{\circ}$ & $+0.83(63 \%)$ \\
\hline Hard & $1.05 \pm 0.41^{\circ}$ & Over 500 & + Over 500 & $1.50 \pm 0.38^{a}$ & $1.22 \pm 0.47^{\circ}$ & $-0.28(19 \%)$ \\
\hline
\end{tabular}


Table 2 - Values in frequency of Ssk/Sk for dentin according to type of brush used.

\begin{tabular}{|c|c|c|c|c|c|c|c|c|}
\hline \multirow{4}{*}{ Brush type } & \multicolumn{8}{|c|}{ Values in frequency (\%) } \\
\hline & \multicolumn{4}{|c|}{ Ssk } & \multicolumn{4}{|c|}{ Sk } \\
\hline & \multicolumn{2}{|c|}{ Before Brushing } & \multicolumn{2}{|c|}{ After Brushing } & \multicolumn{2}{|c|}{ Before Brushing } & \multicolumn{2}{|c|}{ After Brushing } \\
\hline & $\%$ valley (-) & $\%$ peak $(+)$ & $\%$ valley (-) & $\%$ peak $(+)$ & $<3$ & $>3$ & $<3$ & $>3$ \\
\hline Soft & 40 & 60 & 20 & 80 & 60 & 40 & 40 & 60 \\
\hline Medium & 20 & 80 & 20 & 80 & 80 & 20 & 60 & 40 \\
\hline Hard & 20 & 80 & - & - & 80 & 20 & - & - \\
\hline
\end{tabular}

Table 3 - Values in frequency of Ssk/Sk for enamel according to type of brush used.

\begin{tabular}{|c|c|c|c|c|c|c|c|c|}
\hline \multirow{4}{*}{ Brush type } & \multicolumn{8}{|c|}{ Values in frequency (\%) } \\
\hline & \multicolumn{4}{|c|}{ Ssk } & \multicolumn{4}{|c|}{ Sk } \\
\hline & \multicolumn{2}{|c|}{ Before Brushing } & \multicolumn{2}{|c|}{ After Brushing } & \multicolumn{2}{|c|}{ Before Brushing } & \multicolumn{2}{|c|}{ After Brushing } \\
\hline & $\%$ valley $(-)$ & $\%$ peak $(+)$ & $\%$ valley $(-)$ & $\%$ peak $(+)$ & $<3$ & $>3$ & $<3$ & $>3$ \\
\hline Soft & 80 & 20 & 100 & 0 & 80 & 20 & 60 & 40 \\
\hline Medium & 80 & 20 & 80 & 20 & 100 & 0 & 40 & 60 \\
\hline Hard & 60 & 40 & 80 & 20 & 60 & 40 & 100 & 0 \\
\hline
\end{tabular}

groups were done using the Tukey HSD test. Statistical significance was set at .05 . The values $S k$ and $S s k$ were presented in the form of frequency, as they presented variation limits in positive and negative values. There was no statistically significant difference for the substrate enamel before and after simulated toothbrushing, irrespective of the toothbrush hardness, for all parameters analyzed, as well as for dentin with a soft toothbrush. However, the results of parameter $S q$ found for the medium brush showed a significant increase in dentin surface roughness after brushing. Dentin abrasion with the hard brush could not be analyzed because it was defined as being over $500 \mu \mathrm{m}$, in excess of the laser interferometer reading capacity. For the parameter $S s k$, enamel presented predominantly negative values, indicating a larger number of valleys before and after brushing; on the other hand, dentin presented predominantly positive values, indicating a larger number of peaks (Tables 2 and 3). The graphic representation of surface roughness along the analyzed area is represented in Figures 1 ( $\mathrm{A}$ and $\mathrm{B}$ ) and 2 ( $\mathrm{A}$ and $\mathrm{B})$, axonometric images that allow relief to be seen.

\section{Discussion}

The hypothesis tested in this study was accepted only for dentin. The type of brush only influenced the dentin substrate topography and did not harm the enamel surface. Human tooth enamel behavior was similar for the three types of toothbrushes, and presented no significant variation for the parameter $S q$ among the groups, before and after simulated brushing. Dentin presented statistically similar results to those of enamel for the soft brush, but for the medium brush, there was increased surface roughness after brushing. Tooth structure abrasion with the hard-bristled brush was higher than $500 \mu \mathrm{m}$, thus it was not possible to assess the roughness parameters of this structure by the methodology applied.

After the brushing procedure, the enamel surface was not abraded. Because of its highly mineralized content, enamel is extremely hard. ${ }^{26}$ However, when fracture occurs, it is reported as a result of enamel prism disorganization due to stress concentration in the cervical region of the tooth. The action of dentifrices and brush could result in fracture expansion only. ${ }^{1,10,11}$ 


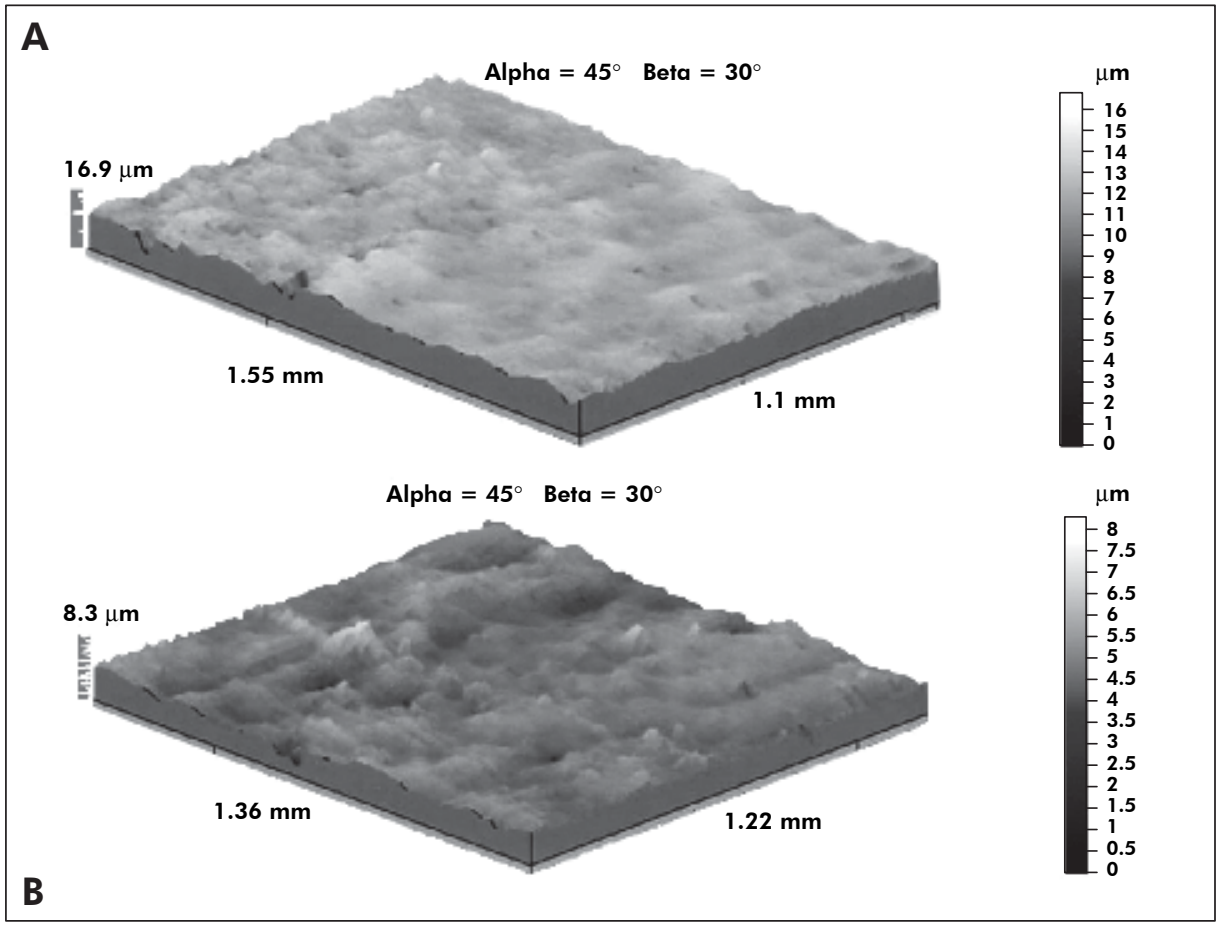

Figure 1, A and B - Surface Topography - $x$, $y$ and $z$ (length, width and height) of analyzed area. A - Dentin roughness before brushing, and B - Increase of dentin roughness after brushing with medium-bristled tooth brush.

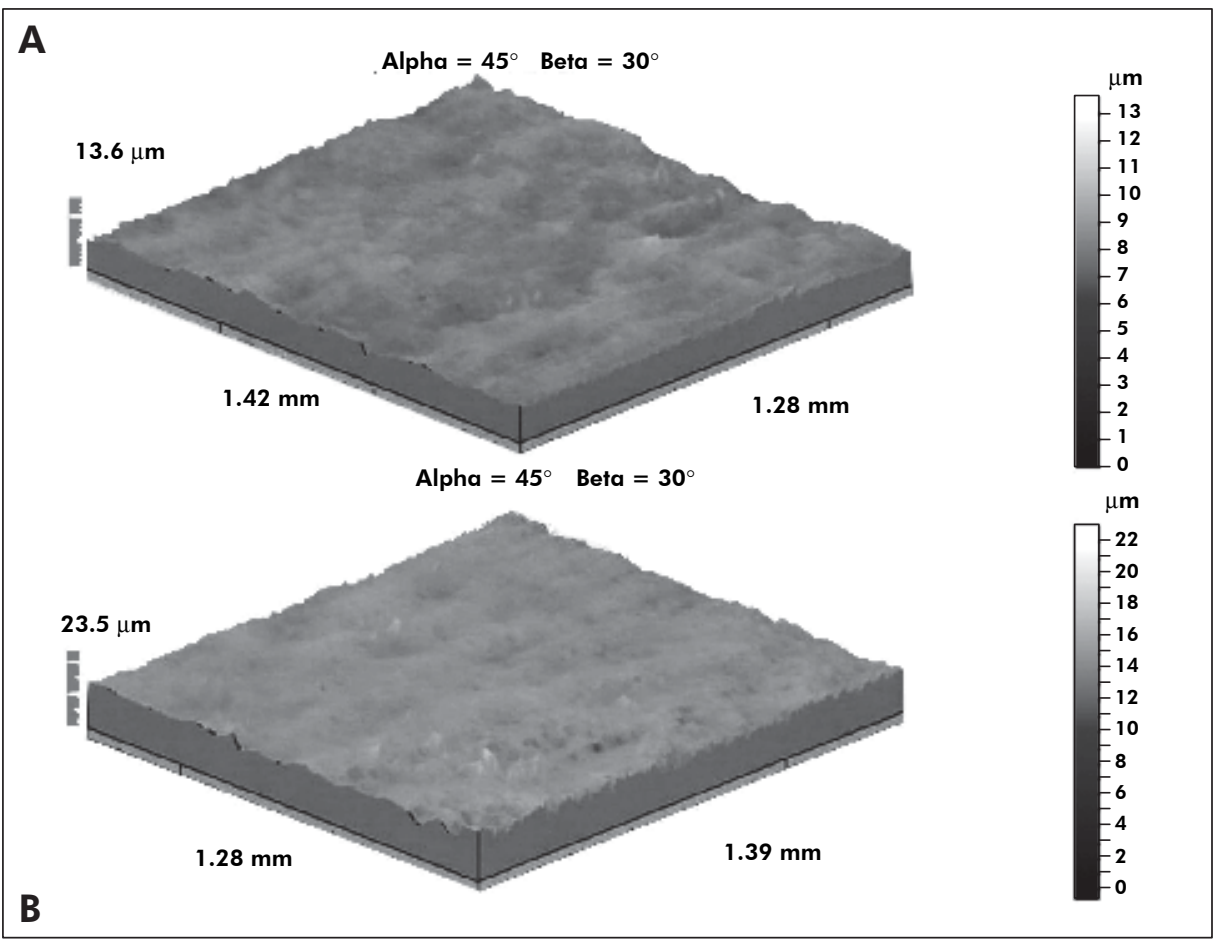

Figure 2, A and B - Surface Topography - $x$, $y$ and $z$ (length, width and height) of analyzed area. A - Enamel roughness before brushing, and B - Enamel roughness presented no significant variation before and after simulated brushing.

With regard to surface form characterization, in this study, dentin presented a symmetry coefficient with a predominance of peaks, and it was more susceptible to abrasion in comparison with the enamel surface, in which valleys were predominant.

Abrasion on the dentin surface was observed in an abrasion test with soft-bristled brushes, ${ }^{20}$ in contrast with the result obtained in the present study, 
in which this type of bristle did not result in abrasion of this structure. However, these authors used a load of $300 \mathrm{~g}$ while, in the present study, the load applied was $200 \mathrm{~g}$. In an abrasion test by means of human dentin brushing, ${ }^{14,16,27}$ there was no significant difference in the abrasion of this structure with regard to toothbrush bristle hardness. On the other hand, a reduction in abrasion was reported when hard bristles were used. ${ }^{19}$ This differs from the results of the present study, in which it was noted that hard-bristled brushes presented greater abrasion in dentin than the other types of bristles.

Abrasion test studies did not observe enamel structure abrasion, ${ }^{13}$ a result in agreement with that obtained in the present study, when soft-, mediumand hard-bristled brushes were used on this same substrate. Other studies related enamel abrasion and abrasion by brushing. ${ }^{20}$ However, in those researches, the abrasion tests were related to exposure to acid and lateral forces, respectively.

To many authors, the abrasive effect of dentifrice on dentin and enamel structure abrasion is related more to abrasive concentration and is hardly influenced by bristle-hardness. ${ }^{15-17}$ Nonetheless, abrasion may be caused by the corrosive effect of the dentifrice combined with the mechanics of the toothbrush bristles. ${ }^{2,8,13}$ As there was no variation in the type of dentifrice used in the present study, it was not possible to relate abrasion and abrasive concentration. However, the results showed that there was no enamel abrasion during the brushing procedure. On the other hand, in dentin, abrasion was observed with

\section{References}

1. Grippo JO, Simring M. Dental "Erosion" Revisited. J Am Dent Assoc. 1995;126(5):619-28.

2. Imfeld T. Dental erosion. Definition, classification and links. Eur J Oral Sci. 1996;104(2):151-5.

3. Levitch LC, Bader JD, Shugars DA, Heymann HO. Non-carious cervical lesions. J Dent. 1994;22(4):195-207.

4. Smith BGN. Toothwear: Aetiology and Diagnosis. Dent Update. 1989;16(5):204-12.

5. Attin T, Knöfel S, Buchalla W, Tütüncü R. In situ Evaluation of Different Remineralization Periods to Decrease Brushing Abrasion of Demineralized Enamel. Caries Res. 2001;35(3):216-22. the use of medium and hard-bristled brushes using dentifrice of medium abrasiveness for both groups, which does show the influence of the type of brush.

Regarding the topography analysis, the roughness parameters can be calculated using two-dimensional (2D) or three-dimensional (3D) study. ${ }^{24} 2 \mathrm{D}$ parameters are used for profile analysis. However, digital techniques of surface analysis in 3D make possible the study of a three-dimensional area of the surface without contacting it. The accomplishment of digital analyses associated to a reading without contact by means of optical instruments in this study made possible the attainment of data without distortions or damages to the surface of enamel and dentine structures, ${ }^{25}$ but the optical reading was sensitive, preventing the attainment of focus in the dentine surface after brushing with hard-bristled brushes due to a resultant wear superior to $500 \mu \mathrm{m}$.

\section{Conclusion}

In accordance with the methodology used and based on the analysis of the data obtained in this study, it was possible to conclude that: Brushing with the use of soft-, medium- and hard-bristled brushes and dentifrice of medium abrasiveness is not capable of abrading human enamel. In dentin, medium- and hard-bristled brushes caused increased surface roughness.

\section{Acknowledgements}

The authors are indebted to the financial support granted by FAPEMIG (Grant no. 160/2004).

6. Attin T, Siegel S, Buchalla W, Lennon ÁM, Hannig C, Becker K. Brushing Abrasion of Softened and Remineralised Dentin: An in situ Study. Caries Res. 2004;38(1):62-6.

7. Braem M, Lambrechts P, Vanherle G. Stress-induced cervical lesions. J Prosthet Dent. 1982;67(5):718-22.

8. Eisenburger M, Shellis RP, Addy M. Comparative Study of Wear of Enamel Induced by Alternating and Simultaneous Combinations of Abrasion and Erosion in vitro. Caries Res. 2003;37(6):450-5.

9. Kuroiwa M, Kodaka T, Kuroiwa M. Microstructural Changes of Human Enamel Surfaces by Brushing With and Without Dentifrice Containing Abrasive. Caries Res. 1993;27(1):1-8. 
10. Lee WC, Eakle WS. Possible role of tensile stress in the etiology of cervical erosive lesion of teeth. J Prosthet Dent. 1984;52(3):374-80

11. Edwin D, Meyer G, Schwartz P. The etiology of wedge-shaped defects: A morphological and function-oriented investigation. J Gnathol. 1991;10(1):49-56.

12. Kliemann C. Lesões Cervicais Não-Cariosas por Abrasão (Escovação Traumática). J Bras Clin Odontol Integr. 2002;6(1):204-

13. Addy M, Hunter ML. Can tooth brushing damage your health? Effects on oral and dental tissues. Int Dent J. 2003;53(3):17786.

14. Bjorn H, Lindhe J, Grondahl HG. The abrasion of dentine by commercial dentifrices. Odontol Revy. 1966;17(2):109-20.

15. Cohen RB. Toothpaste abrasion. J Am Dent Assoc. 2004;135(11):1520-2.

16. Manly RS, Brudevold F. Relative abrasiveness of natural and synthetic toothbrush bristles on cementum and dentin. J Am Dent Assoc. 1957;55(6):779-80.

17. Radentz WH, Barnes GP, Cutright DE. A survey of factors possibly associated with cervical abrasion of tooth surfaces. J Periodontol. 1976;47(3):148-54

18. Svinnseth PN, Gjerdet NR, Lie T. Abrasivity of toothpastes: An in vitro study of toothpastes marketed in Norway. Acta Odontol Scand. 1987;45(3):195-202.
19. Dyer D, Addy M, Newcombe RG. Studies in vitro of abrasion by different manual toothbrush heads and standard toothpaste. J Clin Periodontol. 2000;27(2):99-103.

20. Litonjua LA, Andreana S, Bush PJ, Tobias TS, Cohen RE. Wedged cervical lesions produced by toothbrushing. Am J Dent. 2004;17(4):237-40.

21. Bergström J, Lavstedt S. An epidemiologic approach to toothbrushing and dental abrasion. Community Dent Oral Epidemiol. 1979; 7(1):57-64.

22. Kitchin PC. The prevalence of tooth root exposure, and the relation of the extent of such exposure to the degree of abrasion in different age classes. J Dent Res. 1941;20(6):565-81.

23. Bastos FS, Godoy GCD, Las Casas EB, Buono VTL. Análise da topografia do esmalte dentário. In: $59^{\circ}$ Congresso Anual Internacional da ABM. São Paulo. Anais. 2004. [Cd-Rom].

24. Gadelmawla ES, Koura MM, Maksoud TMA, Elewa IM, Soliman HH. Roughness parameters. J Mater Process Technol. 2002;123(1):133-45.

25. Hutchings IC. Tribology: friction and wear of Engineering Materials. London: Edward Arnold; 1992.

26. Tyldesley WR. The mechanical Properties of Human Enamel and Dentine. Br Dent J. 1959;106(1):269-78.

27. Bjorn $\mathrm{H}$, Lindhe J. Abrasion of dentine by toothbrush and dentifrice. A methodological study. Odontol Revy. 1966;17(1):1727. 